\section{References}

1 Holder TM, Cloud DT, Lewis JE, Jr, Pilling GP. Esophageal atresia and tracheo-esophageal fistula: a survey of its members by the surgical section of the American Academy of Pediatrics. Pediatrics 1964; 34: 542-9.

2 Waterston DJ, Bonham Carter RE, Aberdeen E. Oesophageal atresia: tracheo-oesophageal fistula. A study of survival in 218 infants. Lancet 1962; i: 819-22.

3 Brereton RJ. Skeletal anomalies in oesophageal atresia. $Z$ Kinderchirurgie 1979; 26: 258-70.
4 Cumming WA. Neonatal radiology: esophagea 'atresia and tracheo-esophageal fistula. Radiol Clin $N$ Amer 1975; 13: 227-95.

5 Quan L, Smith DW. The Vater association. $J$ Paediatr $1973 ; 82$ : 104-71

Correspondence to Mr A Azmy, Royal Hospital for Sick Children, Yorkhill, Glasgow G3 8SJ

Received 7 April 1983

\title{
Disseminated arterial calcification associated with acardius acephalus
}

\author{
D ROYSTON AND F GEOGHEGAN
}

\author{
Department of Pathology, National Maternity Hospital, Holles Street, Dublin
}

SUMMARY Widespread arterial calcification was shown at necropsy in an infant who died at age 5 days and whose twin was acardiac. The changes resembled closely those described in idiopathic arterial calcification of infancy and the possible importance of haemodynamic factors in the production of these changes is discussed.

\section{Case report}

A 30 year old woman expecting twins, whose first pregnancy in 1975 had been completely normal, was admitted to this hospital because of ultrasound scan detection of a cystic malformation of 1 baby. Polyhydramnios was also present. There was no history of drug ingestion or smoking. Spontaneous premature labour began at 30 weeks' gestation and twin 1 was delivered by forceps because of cord prolapse at full dilatation. Delivery of twin 2 was by breech extraction under general anaesthesia and the acardiac fetus showed multiple subcutaneous fluid filled cysts, puncture of which was necessary to effect delivery. Twin 2 weighed $1940 \mathrm{~g}$ and displayed the typical features of acardius acephalus. The placenta was removed manually, weighed $920 \mathrm{~g}$, and was bulky, pale, and fragmented and monoamniotic and monochorionic in type. The umbilical cord of twin 2 contained a single artery and vein and was inserted into the cord of twin 1 near its attachment to the placenta. The cord of twin 1 contained 2 arteries and 1 vein.

Twin 1 weighed $1500 \mathrm{~g}$ and had an Apgar score of 9 at 1 and 5 minutes. The baby was in excellent condition and did not require resuscitation. She was admitted to the intensive care unit because of prematurity and remained well until 44 hours of age when her condition suddenly deteriorated and a clinical diagnosis of sepsis was made. Despite treatment she failed to improve and died at age 5 days. Cardiomegaly, hepatomegaly, and signs of neurological abnormality were present before death. Serum calcium values were normal and a metabolic and infection screen were negative.

\section{Necropsy findings}

Important gross findings at necropsy were confined to the heart, lungs, liver, brain, and blood vessels. The heart weighed $19.5 \mathrm{~g}$ (normal $10 \mathrm{~g}$ ). Both ventricles were enlarged but no anatomical abnormalities were found. Both lungs were poorly aerated. The liver was firm and greenish brown in colour. Sections of the brain showed extensive bilateral intraventricular haemorrhage and kernicterus but there was no evidence of intracranial trauma. Patchy calcification was grossly evident in the pulmonary trunk, aortic arch, and in the thoracic and abdominal aorta. The major branches of the aorta were similarly affected.

Microscopic findings. The most striking findings were in the arteries. The elastic laminae of the aorta and pulmonary trunk showed patchy calcification and fragmentation. The media contained large focal calcium deposits that interrupted the elastic fibres (Fig. 1). In addition to the medial calcification, some large pulmonary branches showed focal intimal proliferation without appreciable obliteration of the lumen. The splenic artery showed, in addition to medial changes, an area of calcification along the internal elastic lamia but without intimal proliferation (Fig. 2). Intrathyroid and intrarenal arteries had similar 


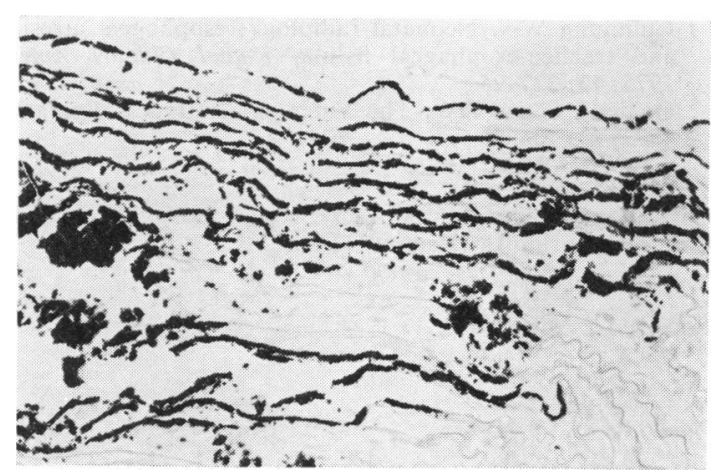

Fig. 1 Aorta calcification of elastic fibres of media (Von Kossa) (× 190).

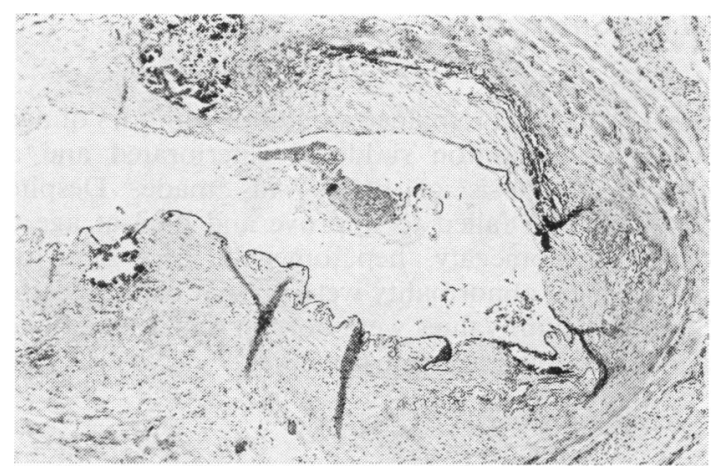

Fig. 2 Area of calcification in splenic artery (haematoxylin and eosin) $(\times 50)$.

changes. The coronary arteries were not affected and no ischaemic or subendocardial abnormalities were present. One large placental artery showed very extensive medial calcification only. The trophoblastic basement membrane was strikingly and extensively calcified. The liver showed cholestasis and focal hepatitis. Patchy tubular calcification was seen in the kidney with atrophy of the lining epithelium. The lungs displayed hyaline membrane formation, pulmonary oedema, and focal intra-alveolar bleeding. The parathyroids were not examined. No arterial lesions were found in the acardiac twin, whose renal tubules were cystically dilated and more extensively calcified than those of twin 1 . The nephrogenic zone was reduced in the cystic areas.

The cause of death was a combination of hyaline membrane disease, intraventricular haemorrhage, kernicterus, and possible infection, although no organisms were isolated. The arterial findings were regarded as incidental and were typical of those previously described as idiopathic arterial calcification of infancy.

\section{Discussion}

This patient is of interest firstly because she seems to be unique and secondly because the arterial findings seem typical of those reported as idiopathic arterial calcification of infancy. The pathogenesis of these changes has been the subject of controversy. ${ }^{12}$ Similar changes have been noted in metastatic arterial calcification secondary to advanced renal disease, in hypervitaminosis $\mathrm{D}$, and in conjunction with anomalies of the heart and great vessels and this latter association suggests a haemodynamic disturbance as the proximate cause. ${ }^{3}$ In this infant all the above predisposing conditions could be excluded with the exception of a haemodynamic disturbance. The role of the tunica media in the pathogenesis of idiopathic arterial calcification of infancy is disputed. Morton $^{2}$ stated that the initial changes affect the internal elastic lamina. Gower and Pinkerton ${ }^{4}$ suggested that calcification of muscle fibres is primary. In our patient calcification of the internal elastic lamina in vessels was present only occasionally. On the contrary, the distribution of calcification in both elastic and muscular arteries was along the elastic fibres of the media. Experimental work by Grasso and Selye ${ }^{5}$ suggests that deposition of calcium in the tissues may be the result of interaction between local and general factors. Thus certain 'calcifying agents' such as parathormone and vitamin D may act as 'sensitisers' and induce a state of altered tissue reactivity in which the affinity of certain tissues for calcium is increased, and for which the term 'calciphylaxis' has been proposed. Experimental 'calciphylaxis' in conjunction with chemically induced alterations of local tissue metabolism may be used to produce calcific deposits in the metabolically modified tissues. If a similar mechanism were implicated in the aetiology of the arterial calcification described here changes in the vessels of the acardiac twin would be expected. No such change was seen, however.

In this infant there is little doubt that abnormal haemodynamic stress existed. In acardius circulation is accomplished by the usually normal twin, in whom cardiac hypertrophy may develop. The blood pursues a reversed course in the acardiac monster via 1 large artery to artery and 1 vein to vein anastomosis. ${ }^{6}$ The placental changes in this infant indicate that the condition existed in utero. Similar cases have been described in stillborn infants. Meyer and Lind ${ }^{8}$ frequently found calcification in the iliac arteries of neonates and suggested that this represents a structural accommodation to the increasing haemodynamic load on the common and internal iliac arteries that receive the full impact of the large placental blood flow. In this infant 
the increased haemodynamic load imposed by the acardiac twin may have had a similar effect on the vasculature. Indeed, the striking cardiomegaly supports this view.

It is conceivable that similar stresses sustained during intrauterine life, though in a less severe degree, may predispose to the later development of the arterial changes associated with so called idiopathic arterial calcification of infancy. It is advisable therefore that when this unusual condition is detected the obstetrical background of the child is closely scrutinised.

We thank Mr J Byrne and Mr P Dingle for their technical assistance and Dr J Bannigan for helpful suggestions and review of the manuscript.

\section{References}

1 Moran JJ. Idiopathic arterial calcification of infancy-a clinicopathological study. Pathol Annu 1975; 10: 393-417.
2 Morton R. Idiopathic arterial calcification in infancy. Histopathology 1978; 2 : 423-32.

3 Moran JJ, Steiner GC. Idiopathic arterial calcification in a 5 year old child. Amer J Clin Pathol 1962; 37: 521-6.

4 Gower ND, Pinkerton JRH. Idiopathic arterial calcification in infancy. Arch Dis Child $1963 ; 38$ : 408-11.

5 Grasso S, Selye H. Calciphylaxis in relation to the humoral production of occlusive coronary lesions with infarction.J Pathol Bacteriol 1962; 83 : 495-500.

6 Benirschke K, Kim CK. Multiple pregnancy (Part 1). N Engl J Med 1973; 288: 1276-84.

7 Liu CT, Singer DB, Frates R. Idiopathic arterial calcification in infancy. Arch Pathol Lab Med 1980; 104: 589-91.

8 Meyer WW, Lind J. Calcifications of Iliac arteries in newborns and infants. Arch Dis Child 1972; 47: 364-72.

Correspondence to Dr D Royston, Department of Pathology, National Maternity Hospital, Holles Street, Dublin.

Received 3 May 1983 